\title{
The Cultivation of Self-efficacy in College English Learning
}

\author{
Yongping Zhang ${ }^{1}$ and Zaibo $\mathrm{Li}^{2}$,*
}

\author{
${ }^{1}$ School of Foreign Languages, Shaoguan University, Shaoguan, Guangdong 512005, China \\ ${ }^{2}$ School of Chemistry and Civil Engineering, Shaoguan University, Shaoguan, Guangdong 512005, China \\ *Corresponding author. Email: lzb381598@163.com
}

\begin{abstract}
In order to improve the effect of college English learning, it is very necessary to cultivate students' selfefficacy. Self-efficacy theory has extremely high theoretical and practical value for teaching. The mechanism of self-efficacy on English learning is analyzed, and the effective ways to improve English teaching and students' comprehensive application ability are explored in this paper. The key to solving the problem of selfefficacy is that teachers change their teaching concepts and provide students with ways and opportunities to experience success through humanized teaching activities.
\end{abstract} Keywords: self-efficacy; college English; listening and speaking teaching

\section{INTRODUCTION}

Self-efficacy is a core concept put forward by American psychologist Bandura in the theory of social learning [1]. Bandura believes that people's judgment of their abilities plays a major role in their self-regulation system, and thus put forward the concept of self-efficacy. Self-efficacy refers to an individual's ability to judge whether he can complete an activity at a certain level, beliefs, or subjective self-control and feelings. It affects people's choice of behavior, degree of effort, persistence of behavior, emotional response mode and thinking mode, and its basic feature is to emphasize the necessity of subjective factors for learning and the decisiveness of human potential. Bandura also believes that people accept and integrate efficiency information from direct experience, alternative experience, verbal persuasion, and physical and emotional states in the course of activities to form a sense of selfefficacy. These four aspects have also become important dimensions to consider when cultivating and improving self-efficacy. Self-efficacy in turn regulates human activities by influencing the individual's cognitive process, motivation process, emotional process and selection process [2].

Self-efficacy theory has received extensive attention in many fields such as psychology and organizational behavior, and it is no exception in the field of education. A number of scholars have studied the characteristics of college students' self-efficacy and the ways to cultivate them from the perspective of college students' health education [3, 4], explored the influence of self-efficacy in university classroom interaction, and studied the relationship between self-efficacy and English learning performance through empirical research. These results provide inspiration and reference for applying self-efficacy theory to college English teaching. College English listening and speaking teaching is an important way to achieve the goal of college English training and enable college students to communicate effectively in English in their study, work and social interactions. Due to many years of test-taking orientation, Students' English proficiency in China is generally low, and there are problems such as difficulty and lack of self-confidence in the cultivation of English listening and speaking ability. Through the introduction of self-efficacy theory into college English teaching, it aims to better improve college students' confidence and belief in English application ability, stimulate their enthusiasm and initiative, and improve college English teaching effects through the guidance from the inside out.

\section{THE MECHANISM OF SELF-EFFICACY ON ENGLISH LEARNING}

Bandura believes that self-efficacy realizes its subjective mechanism through mediations such as choice, thinking, motivation, and physical and mental reactions. The effect of self-efficacy on students' English learning is mainly realized through these four processes [5].

The first is the selection process. Self-efficacy affects students' choices of English learning environment and learning behavior activities. Students with a strong sense of self-efficacy often choose a challenging learning environment. They actively participate in various higherdifficulty language learning activities to improve their ability to use English, which in turn enhances their sense of self-efficacy. However, students with low self-efficacy avoid challenging environments and find it difficult to speak English in English learning. They often choose to remain silent and in a passive situation.

The second is the thought process. Bandura pointed out that the actions of individuals must be dominated by thinking, and one of the main functions of thinking is to 
enable people to predict future behavior results. Selfefficacy produces self-promotion or hindrance to students' English learning through the thinking process. First of all, the student's goal setting is affected by the ability assessment. Students with a strong sense of self-efficacy believe that they can effectively analyze, think and train in complex English learning tasks, and the goals set are challenging. Secondly, self-efficacy affects students' situational expectations. Students who believe in their English learning ability tend to imagine successful language use scenes. However, students with low selfefficacy will imagine the scene of failure, which hinders their own learning and practice.

The third is the motivation process. Self-efficacy affects the motivation and maintenance of students' learning motivation, determines the level and intensity of learning motivation, and is reflected in the degree of effort in learning activities and the endurance and endurance in the face of difficulties and failures. Students who have a stronger sense of self-efficacy for English learning have stronger motivation to learn English well, and have stronger toughness and persistence when encountering difficulties and setbacks. However, students with low selfefficacy are prone to abandon themselves when they encounter difficulties in English expression and communication.

The last is the physical and mental reaction process. The sense of self-efficacy determines the emotional response of students, such as emergency state, anxiety and depression, and affects their alertness to potential threats. When students think they have the ability to deal with the potential difficulties in the use of English, they will not feel worried and afraid before using them, and can actively participate in communication training, improve their English level, enhance their self-efficacy beliefs, and form a virtuous circle. However, students with low self-efficacy always doubt their English expression ability, fear and worry about possible difficulties, which reduces their learning efficiency.

\section{WAYS TO STRENGTHEN SELF- EFFICACY IN ENGLISH LEARNING}

The current college English teaching advocates a "studentcentered" teaching model, and encourages students to rely on the Internet and multimedia to carry out personalized and autonomous learning. Obviously, the autonomous learning model puts forward higher requirements on the psychological qualities that learners should possess. In a sense, the success of learning activities depends on learners' attitudes towards the world, especially learning activities, and their learning desires. It is an unrealistic illusion to implement autonomous learning strategies in the state of pervading students' negative emotions. An important prerequisite for guiding students to learn independently is to pay attention to the emotional factors of students in teaching and eliminate their negative and resisting emotions towards English learning. Low self- efficacy is a prerequisite factor for negative emotions, and there is a circular and enlarged relationship with negative emotions and inefficient learning behaviors [6]. Therefore, measures to strengthen self-efficacy can solve the source of inefficient English learning. How to strengthen selfefficacy is a major issue in educational practice. According to Bandura's self-efficacy theory, appropriate external reinforcement, self-reinforcement and attribution training can help enhance students' sense of self-efficacy. No matter which kind of strengthening method, in the final analysis, it must reflect a kind of humanized care for students. Combining the curriculum characteristics of college English teaching, teachers can strengthen through direct emotional integration and indoctrination, and can also increase students' achievement experience through course teaching, and indirectly achieve the goal of strengthening students' sense of self-efficacy in English learning.

\subsection{Direct Reinforcement}

Direct reinforcement refers to the measures that teachers pay attention to the emotions of students outside of the curriculum, that is, teachers directly intervene in students' self-efficacy by means of harmonious teacher-student relationship, guiding students to correct attribution and language persuasion.

\subsubsection{Increasing opportunities for communication}

College English is a public basic course. Teachers and students belong to different teaching departments. There is a lack of identity and belonging between teachers and students. The communication between teachers and students is purely a kind of teaching communication. The lack of necessary communication and understanding between teachers and students will inevitably produce a sense of distance and indifference, which will undoubtedly affect the classroom atmosphere and students' mentality. Therefore, in this specific teaching environment, teachers should consciously increase the time and space and opportunities for teacher-student interaction. In addition to classroom communication, teachers can also communicate with students extensively through informal chats between classes, talking to individual students, holding class meetings, organizing English salons, and sending e-mails. Students can get emotional release and emotional expression opportunities in communication, and teachers have also found a breakthrough in linguistic hints and persuasion to students. Effective communication behavior is a quick and effective way of self-efficacy training, which can increase students' love for teachers, interest in courses, desire for in-depth thinking, and confidence in completing tasks in a short period of time. 


\subsubsection{Preventing extreme tendencies in the attribution process}

When college students encounter English learning difficulties, a bad attribution tendency is to attribute their failures to internal uncontrollable factors such as insufficient ability and lack of language learning talent. This negative attribution tendency provides a basis for continued failure expectations. Therefore, teachers should provide active attribution counseling to students. For unsuccessful performance, it is necessary to guide students to attribute internal but controllable factors, such as insufficient knowledge or insufficient effort, so that they can see the hope of success. Quite a few students are poor in basic language skills, have a small vocabulary, and have the desire to learn English well but lack the motivation for behavior. One of the fundamental reasons is the lack of self-efficacy caused by the negative attribution tendency.

\subsection{Indirect Reinforcement}

College students are already adults, their personalities have been finalized, and their worldviews have taken shape. The indirect enhancement of self-efficacy is more effective and especially important. Indirect reinforcement is achieved by increasing the achievement experience of individual behavior. The psychological mechanism is that if the individual obtains an experience of achievement in the activity, this experience becomes an attractive inducement, which makes the individual increase the psychological expectation of similar activities [7]. In teaching activities, teachers create an environment for students' learning success and build a "platform" to allow students to experience happiness and success in learning activities, change negative thinking and emotional trends, and improve self-efficacy.

\subsubsection{Setting up progressive teaching goals}

For students with low self-efficacy, teachers should pay attention to gradients and levels when helping them to formulate learning goals. The correct learning goals are: (1) near-end rather than far-end; (2) specific rather than overall; (3) moderately challenging and not too difficult or too easy. What is puzzling is that the overall goal of college English teaching in China interferes with the daily teaching goals and the students' usual learning goals. Students are usually required to reach a high level or a certain level of listening, speaking, reading, writing, and translation, or require several levels (usually divided into one, two, three, and four levels according to the semester). The behavior of replacing specific teaching goals with syllabus goals is bound to dampen students' enthusiasm. Teachers should set teaching goals according to the specific conditions of students, and put forward specific and recent requirements for students of different levels. When students move towards the set goals and get feedback on their progress, their self-efficacy is confirmed and improved. When selfefficacy improves, effort, endurance, and skills also increase. In short, the goal of daily teaching is to let students see hope and germinate confidence. Reading a passage, reciting a few sentences, or even dictating a few words are enough to excite students who have lost their sense of self-efficacy. They will regain their confidence in learning from the success experience bit by bit.

\subsubsection{Using achievement-experience-based teaching methods}

Anxiety and fear in listening and speaking are the focus of English learning. There are many psychological reasons for being afraid of listening and speaking, and another important reason is the lack of "assuming" in listening and speaking-the basics of reading and writing. The impetuous style of study under the test-oriented education model causes students to lack productive vocabulary, weak sentence awareness, and lack the ability to quickly generate phrases and sentences required for oral production. In this case, asking to hear and hear first is equivalent to driving a land-duck into the water, and students will lose the minimum sense of self-efficacy. Reading and writing are the most secure language input and output modes that students feel. The teaching mode of reading and writing as the basis and promoting listening and speaking through reading and writing allows students to experience gains and success in reading and writing, and then use a stable reading Write the basics and redouble your self-confidence to improve your listening and speaking skills. Ignore the language errors that students make when writing, and encourage students to make improvements first, let go of writing, write boldly, write confidently, write expressive skills, and gain a sense of accomplishment. A sense of accomplishment can in turn enhance the confidence and desire of English learning, changing "I am required" to "I require". The entry point of writing can be sentences, short paragraphs, diaries, advertisements, letters, resumes, and then transition to propositional essays. W can also design some exploratory questions, essays, and research reports based on the content of the text. Students are required to find materials after class and then complete the writing task Let students "write while reading" and "read while writing", integrating reading and writing. Sufficient reading and writing cycles and sufficient reading and writing conditions can strengthen the integrity of the language itself, achieve the purpose of promoting listening and speaking with reading and writing, shorten the distance between language knowledge and application ability, and ultimately enhance students' self-efficacy in the successful experience of language learning sense. 


\subsubsection{Paying attention to the process of teaching evaluation method}

The evaluation system of English courses should reflect the diversification of evaluation subjects and the diversification of evaluation forms. Evaluation should focus on the development process of students' comprehensive language use ability and the effect of learning, and adopt a combination of process evaluation and summative evaluation, focusing on both the results and the process, so that the evaluation of the learning process and the learning results can be harmoniously unified. However, there is a misunderstanding in the current evaluation methods of college English teaching. Summative evaluation has received extreme attention, while process evaluation has not yet risen to the agenda. The summative evaluation promotes the atmosphere of test-oriented education, intensifies the abnormal comparison psychology between classes and schools, and brings great psychological pressure to students in learning. On the other hand, the summative evaluation prolongs the feedback of teaching information. During the cycle, students cannot feel the joy of their progress and success in a timely manner. The current teaching situation requires an evaluation method that allows students to recognize themselves, so as to realize independent learning and independent development. Formative evaluation is just such an evaluation method. Its task is to evaluate the performance of students in the daily learning process, the achievements they have achieved, and the development of emotions, attitudes, and strategies reflected. Its purpose is to motivate students to learn, to help students effectively regulate their own learning process, to enable students to gain a sense of achievement and enhance their sense of self-efficacy.

\section{PROBLEMS TO BE PAID ATTENTION}

In view of the characteristics of college English listening and speaking teaching and college students' sense of selfefficacy, we should pay attention to the following points in the practice of college English teaching based on selfefficacy

\subsection{Giving Priority to Moderate Encouragement}

Because the self-efficacy of college students is at a sensitive and unstable stage, especially for the underachievers, their self-efficacy is easily affected by frustration and reduced. Therefore, teachers should fully understand their self-efficacy in the teaching of English listening. On the sensitivity, grasp the scale. When dealing with students' mistakes, they should provide positive feedback on the basis of positive encouragement, while maintaining and promoting their result expectations and effectiveness expectations, so as to help them recognize the gaps, redouble their efforts, and catch up.

\subsection{Supporting the Grading Teaching}

We should strengthen the sense of self-efficacy of college students. The principle of teaching students in accordance with their aptitude must be reflected in the teaching of college English listening and speaking, and a hierarchical teaching system must be implemented according to the abilities of students. Otherwise, the "one pot of stew" will inevitably lead to some students who are more than enough in classroom learning and have little harvest, while some students feel more strenuous and have low grades, and it is difficult to achieve the purpose of strengthening selfefficacy.

\subsection{Paying Attention to Gender Differences}

Although studies have shown that girls have certain advantages in language learning, due to cultural habits and personality characteristics, girls are generally weaker in self-efficacy compared with boys. So teachers should consciously give them more opportunity to show themselves in college English listening and speaking teaching, so as to enhance their self-confidence and enterprising consciousness and help them improve their self-efficacy in college English listening, speaking, learning.

\section{CONCLUSION}

In college English classes, students' self-efficacy plays an important role in the development of teaching activities and classroom interaction. As one of the important factors of students' learning attitude, cultivating and improving students' self-efficacy is also the teaching goal of college English classrooms. Students' self-efficacy is a complex psychological variable, which is closely related to students' emotions, the relationship between teachers and students, and the teaching environment. These factors will be directly or indirectly reflected in the performance of students' classroom interaction. The essence of the negative emotion of college students in English learning is a problem of self-efficacy. Teachers' direct emotional intervention can awaken students' depressed will and increase their confidence in behavior. However, the key to solving the problem of self-efficacy is that teachers change their teaching concepts and provide students with ways and opportunities to experience success through humanized teaching activities. Only when students have a high sense of self-efficacy, they will actively and persistently invest in English learning, participate in oral activities, and improve learning efficiency. Only in this way can we meet the everchanging and developing social needs. 


\section{ACKNOWLEDGMENT}

This research was financially supported by the Teaching Reform Project of Shaoguan University (SYJY20192047)

\section{REFERENCES}

[1] A. Bandura, "Human agency in the social cognition theory,". American Psychologist, vol. 9, pp. 75-551, 1989. DOI: https://10.1037/0003-066x.44.9.1175

[2] A. Bandura, "On the Functional Properties of Perceived Self-Efficacy Revisited," Journal of Management, vol. 38, pp. 9-44, 2012. DOI: https:// $10.1177 / 0149206311410606$

[3] H. Metussin, "Gender Imbalance in Brunei Tertiary Education Student Populations: Exploring English Language, Self-Efficacy and Coping Mechanisms as Possible Causes," Review of European Studies, vol. 7, pp. 67-74, 2015. DOI: https:// 10.5539/res.v7n12p67

[4] M. Liu, "The Effect of Mobile Learning on Students' Reading Self-Efficacy: A Case Study of the
APP English Liulishuo," English Language Teaching, vol. 13, pp. 91-95, 2020. DOI: https:// 10.5539/elt.v13n12p91

[5] A. Bandura, "Much ado over a faulty conception of perceived self-efficacy grounded in faulty experimentation," Journal of Social and Clinical Psychology, vol. 26, pp. 641-658, 2007. DOI: https:// 10.1521/jscp.2007.26.6.641

[6] Law Q P S, "Enhancement of Self-efficacy and Interest in Learning English of Undergraduate Students with Low English Proficiency through a Collaborative Learning Program," Biochemical Education, vol. 17, pp. 140-141, 2015. DOI: https:// 10.12691/education-3-1012

[7] Q. Zhang, “The Relationship between Foreign Language Classroom Anxiety and English Performance: The Mediating Effect of General Self-efficacy," Journal of Social Science and Education Research, vol. 3, pp. 37, 2020. DOI: https://10.6918/IJOSSER.202011-3 (11).0003. 